\title{
EDUCAÇÃO INCLUSIVA: EXPERIÊNCIAS DE SALA DE AULA E METODOLOGIA DE ENSINO EM GEOGRAFIA
}

\author{
Brendo Bentes Gemarque \\ Graduando em Geografia pela Universidade Federal Oeste do Pará. \\ E-mail: brendobrasilgeo@gmail.com \\ Ednéa do Nascimento Carvalho \\ Universidade Federal do Oeste do Pará. \\ E-mail: edneiancar@yahoo.com.br
}

\begin{abstract}
RESUMO
O presente estudo apresenta reflexões sobre a inovação na metodologia e no ensino da Geografia em relação a educação inclusiva de pessoas com deficiência mediante a relatos de experiências de sala de aula de professores no ambiente escolar e no ensino remoto, do município de Oriximiná - PA. A pesquisa resulta de uma análise bibliográfica, autores como: Preti (1996), Paulo Freire (1979), Bueno (1999), Camargo (2006; 2016), Pontuschka et al (2007) e Miranda e Mourão (2010) dialogando com temática abordado e a partir de coleta de dados de entrevistas mediatizado pelas ferramentas do Google forms e do Google Meet realizado no segundo semestre de 2020, com 3 (três) professores, sendo dois lecionando no Ensino Fundamental I e o outrem no Ensino Fundamental II. Neste sentido, a necessidade de se repensar em fazer Geografia em sala de aula recorrendo a matérias recicláveis, a objetos disponíveis de fácil acesso, de referências vivenciadas, de conhecimento empírico e cientifico mostrando um contínuo ensino aprendizagem do docente lecionado e do aprendiz em sala de aula. Ainda, o estudo aponta para questões multissensorial do educando, bem como a quebra de paradigma da percepção das pessoas com deficiência e que as práticas sejam concomitantes com as peculiares de cada indivíduo.
\end{abstract}

Palavras-chave: Ensino de Geografia. Educação Inclusiva. Ensino Remoto. Sala de Aula.

\section{INTRODUÇÃO}

Historicamente, a educação inclusiva foi proposta a partir de intensos discursos sociais e políticos, que propuseram defender o direito da pessoa com deficiência ao acesso e concomitante a participação no processo de ensino aprendizagem de qualidade no ensino regular, garantido acessibilidade, igualdade e recursos assistivos do Atendimento Educacional Especializado - AEE levando em consideração as especificidades de cada indivíduo descrito na Constituição Federal inspirada na Declaração dos Direitos Humanos de 1988.

Podendo ainda elencar os subsequentes movimentos nacionais que reivindicaram por planos de ações e de políticas alternativas participativas às entidades de deficientes físicos e associações semelhantes a estes que se identificavam com a causa pela luta de seus direitos e o respeito a pessoa com deficiência, transtornos globais e do desenvolvimento de altas habilidades/superdotação, que dentre os marcos 
legais no Brasil a construção do Estatuto da Criança e do Adolescente (1990) onde ratifica em suas bases o dever dos pais ou responsável legal a matricular na rede pública de ensino regular; e nessa perspectiva, a ocorrência de eventos e organizações internacionais, como a Declaração de Salamanca (1994) de princípios, políticas e práticas norteadores descrevendo o acomodamento de todas as crianças sem distinção no ambiente educacional e logo, a busca por mecanismos pedagógicos que atendam as variedades de sujeitos e da integração da pluralidade de todos.

Em 1996 foi promulgada a Lei de Diretrizes e Bases da Educação Nacional (LDB) - Lei de no 9.394 determinando as diretrizes da Educação Nacional, do direito à educação e do dever de educar e bem como, nas suas descrições no Capítulo V, referência a Educação Especial e assegura aos alunos condições necessárias de adequação de currículo, recursos didáticos, espaço adequado e do atendimento educacional ou serviço especializado em sala de aula, do educandário.

Tais marcos legais evoluíram após vários momentos de lutas e resistências sendo consolidado na atual Lei Brasileira de Inclusão (Lei no 13.146/15), dando visibilidade a necessidade de garantir a inclusão das pessoas com deficiência na sociedade e dando autonomia aos mesmos em diversas áreas de atuação e do campo das ciências afins.

Diante do disto, suscitaram algumas indagações acerca da Geografia e de seu ensino em relação a educação inclusiva, na execução de exercícios em sala de aula da compreensão do espaço geográfico a discentes com alguma deficiência apresentada e a formação continuada aos professores sobre a Educação a Distância, assim como analisar o desenvolvimento de ensino aprendizagem dos alunos com deficiência inseridos no contexto de aulas remotas.

Nesta perspectiva, o objetivo desta pesquisa é refletir sobre as metodologias utilizadas no ensino da Geografia em relação a inclusão de pessoas com deficiência mediante a relatos de experiências de sala de aula de professores no ambiente escolar e no ensino remoto, do município de Oriximiná - PA, permitindo dar subsídios para aprimorar as atividades durante o período vivenciado de pandemia, englobados ao Ensino a Distância.

\section{REFERENCIAL TEÓRICO}

Diante do cenário da pandemia ocasionado pelo Covid-19 impôs-se o isolamento social, mudanças de hábitos e costumes, restruturação em vários setores, 
como: da indústria, dos serviços de bens e consumo, do turismo, da economia incluindo a educação, por consequência, dando andamento a utilização de novas tecnologias e mecanismos de readaptação as relações sociais e acesso às informações.

Sendo assim, é de grande valia que o espaço educacional se constitua com parâmetros arquitetônicos inclusivos e de práticas pedagógicas promovendo a formação de seu alunado por meio de tecnologia assistiva e de material adequado ao entendimento das representações sociais e de conhecimentos das múltiplas dimensões da realidade de mundo, bem como compreender as transformações do seu contexto em volta. E a Geografia, como ciência da sociedade e da natureza permite que o indivíduo assuma posições de produtor de conhecimento e agente de mudança no espaço e de contextualizar a dinâmica de uma sociedade sob a influência das transformações econômicas, crises mundiais, fatores de saúde, fenômenos naturais e assim por diante.

De acordo com Pontuscka et al (2007), ao falar do espaço educacional e das transições que perpassa o ensino aprendizagem da Geografia diz que é preciso pensar nas concepções e práticas baseadas nos princípios da disciplinaridade, transversalidade e interdisciplinaridade da Geografia com as demais ciências na ruptura de metodologias tradicionais que minimizam o conhecimento. Permitindo o aprofundamento do objeto de estudo da Geografia perante outras disciplinas e possibilidades de entendimento, contextualização e assimilação de situações do próprio ambiente de vida.

Realizar essa observação do cotidiano na busca de explicações favorece a produção de novos conhecimentos compreendo o mundo em que está inserido. E nesta perspectiva que o ensino da Geografia se inseri na formação de aprendizado do educando convidando-o a assumir posições diante dos problemas do espaço geográfico usando diferentes métodos, linguagens e técnicas na leitura da sociedade, na natureza do homem.

A esse respeito Paulo Freire (1979) ressalta que:

\footnotetext{
Não é possível fazer uma reflexão sobre o que é educação sem refletir sobre o próprio homem. [...] comecemos por pensar sobre nós mesmos e tratemos de encontrar, na natureza do homem, algo que possa constituir o núcleo fundamental onde se submete o processo de educação. Qual seria este núcleo palpável a partir de nossa própria experiência existencial? Este núcleo seria o inacabamento ou a inconclusão do homem (FREIRE, 1979, p. 27).
}

A educação na sociedade tem o papel de humanizar o homem em sua incompletude. O ser humano em um contexto histórico e social necessita da educação, 
seja ela formal, baseada no compartilhamento de conhecimento numa instituição de ensino, organizada e hierarquizada, ou a educação informal, aprendizado adquirido dos pais e passado aos filhos, de geração a geração. Tais situações, consideradas fundamentais no processo de desenvolvimento humano, que uma vez tendo conhecimento do mundo em sua volta, auxilia na transformação de sua realidade enquanto um indivíduo formado.

Dessa forma, reconhecer a educação como processo humanizador é acolher todas as diferenças do indivíduo sejam respeitadas e se aprenda a viver nessa interação de diversidade social, levando a um crescimento e amadurecimento intelectual, socioemocional, profissional e pessoal. É diante de uma educação humanizadora que favorece o atendimento educacional denominado nos anos de 1980-90 a inclusão escolar. A inclusão permitia a inserir discentes excluídos e esquecidos por suas limitações e alocar a vida educacional e social a um pleno desenvolvimento de exercício de cidadania e da dignidade humana (MIRANDA\&MOURÃO, 2010).

A ideia de educação inclusiva é atender a todas as pessoas com suas peculiaridades através da sua inserção num ambiente educacional, respeitando e cooperando com a igualdade de condições de acesso aos saberes. A priori a escola necessita se adaptar as novas tecnologias assistivas, ao contexto de ensino remoto, trabalhar com a interdisciplinaridade e outrossim, superando os desafios da inclusão. A esse respeito, novamente Miranda e Mourão apud Bueno (1999) nos diz:

\footnotetext{
Não podemos deixar de considerar que a implementação da educação inclusiva demanda, por um lado, ousadia e coragem, mas, por outro, prudência e sensatez, quer seja na ação educativa concreta (de acesso e permanência qualificada, de organização escolar e do trabalho pedagógico e da ação docente) ou nos estudos e investigações que procurem descrever, explicar, equacionar, criticar e propor alternativas para a educação especial (BUENO, 1999, p.9).
}

A proposta de efetivação da prática educacional inclusiva ainda suscita questionamentos quanto a ligação das tecnologias com a educação via remotamente, podendo apresentar uma certa exclusão digital, por outro lado, é um forte aliado à ampliação de informação e de compartilhamento de notícias, bem como para uso de comunicação, interação e melhoramento das metodologias pedagógicas de ensinar e aprender, como é o caso dos professores em formação continuada. 
Diante disso, o ensino a distância (ou educação a distância) atua como mediador entre o professor-aluno e é uma ferramenta que disponibiliza aulas com entretimento oferecendo web conferência, workshops, correio elétrico entre outros. São meios que dão suporte alternativos ao professor facilitado o desenvolvimento cognitivo, lógico e propagação cientifica.

Para Mourão (2010) apud Preti (1996, p. 27), afirma sobre a EaD como:

[...] uma alternativa pedagógica de grande alcance e que deve utilizar e incorporar as tecnologias como meio para alcançar os objetivos das práticas educativas implementadas, tendo sempre em vistas as concepções de homem e sociedade assumidas e considerando as necessidades das populações a que se pretende servir [..] Deve ser compreendida como uma prática educativa situada e mediatizada, uma modalidade de se fazer educação, de se democratizar o conhecimento.

Para Mourão (2010, p. 64) ressalta que:

[...] EaD como alternativa para formação continuada de professores, aliada às tecnologias como agente de mudanças e transformações das práticas pedagógicas, pela qual o aluno é instigado a investir em sua formação, propiciando-se de conhecimento, numa relação mais dialógica com os atores envolvidos no contexto, formando uma rede colaborativa, em os aspectos da interatividade são reforçados e a autonomia valorizada.

Retificando, que a educação inclusiva deve ser entendida como promotora de igualdade e relacionamento a todos os alunos com deficiência e aos discentes que não possuem deficiência, enfatizando o respeito mútuo e assegurar os direitos aos serviços comuns e do acesso a instituições de ensino. Ademais, é preciso superar os desafios existentes da inclusão, construindo pontes de relacionamento entre comunidade, família, entidades governamentais e a escola e acolhê-los no espaço educacional, assim proporcionar a participação e a aprendizagem dos mesmos, levando em consideração as diferenças de cada aluno. Sobre isso Camargo (2006; 2016, p. 25) discorre:

[...] docentes em formação precisam se envolver na esfera teórico-prático com os temas da inclusão e das necessidades educacionais especiais tendo como plano de fundo o paradigma de heterogeneidade e o trato com a identidade e a diferença, não somente de forma apartada em um curso, mas transversalmente em todas as disciplinas. Precisam superar mitos sobre as pessoas com deficiência, principalmente aquele que entende tal característica como algo que superestima ou impossibilidade.

De forma que reconheçam a multissensonriedade do educando, como o tato, a audição, a visão, o paladar e o olfato que é fundamental para o processo de ensino 
aprendizagem como porta de entrada de informações e percepções internas e externas da diversidade sensorial e da linguagem, que caracterizam o ser humano. Considerando o conceito da didática multissensorial ou descrita por Carmago, o termo multissensorialidade, permite ao aluno com/ sem deficiência captar estímulos do ambiente inserido fomentado a capacidade de relacionar os processos sintéticos a partir dos órgãos dos sentidos do corpo e analíticos da perspicácia de observação dando significado a construção de aprendizado do discente (CAMARGO, 2016).

E nesta realidade a necessidade de se repensar em fazer Geografia em sala de aula. Com isso, conduzir o ensino de Geografia adequando a metodologias quer seja lúdica e lógicas desenvolvendo atividades com saberes da realidade do aluno, da própria vida; matérias como jornais e revistas relevantes do contexto do local de moradia; mapas táteis visando o reconhecimento de localização e dimensões dos continentes; com orientações gestuais - libras, dinâmica com o corpo de noções de orientação espacial; trabalhos a campo de visitas em museus, parques, lugares paisagísticos etc.; e a utilização de tecnologias disponíveis como aparelhos móveis. Assim o professor pode experimentar diferentes desafios juntamente com seus alunos e levando a reflexão dos conteúdos geográficos, recorrendo a matérias recicláveis, de referências vivenciadas, de conhecimento empírico e cientifico para a promoção de inclusão e na interação em sala de aula.

\section{CONSIDERAÇÕES FINAIS}

A presente pesquisa resulta de uma análise bibliográfica e a partir de coleta de dados de entrevistas mediatizado pelas ferramentas do Google forms e do Google Meet realizado no segundo semestre de 2020, com 3 (três) professores, sendo dois lecionando no Ensino Fundamental I e o outrem no Ensino Fundamental II. Onde os relatos contados contribuíram significativamente para esta construção de escrita cientifica demostrando suas próprias experiências de vida, enquanto ministrantes a alunos com deficiência em contextos de salas de aula inclusivas e atividades remotas. Podendo ainda citar no diálogo, questões como: busca de aprimoramento da metodologia de ensino, de formação docente continuada e de restruturação curricular, e a falta de suporte em alguns casos de profissionais do Atendimento Educacional Especializado AEE. 


\section{REFERÊNCIAS}

CLAUDIA, D. et al. Professor e surdez: cruzando caminhos produzindo novos olhares. Uberlândia: EDUFU, 2009.

CAMARGO, E. P. de. Inclusão e necessidade especial: compreendendo identidade e diferença por meio do ensino de física e da deficiência visual. São Paulo: Editora Livraria da Física, 2016.

PONTUSCHKA, N. N. Paganelli, I. T. Cacete, H. N. Para ensinar e aprender

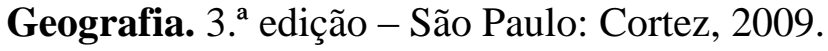

PERNAMBUCO, Ministério Público do Estado de. Educação Inclusiva: marcos legais e perspectivas de ações para implementação. Santos, D. C. C. S. Macêdo, L. E. de M. Organização: Centro de Apoio Operacional às Promotorias de Defesa do Direitos Humanos à Educação - CAOP Educação; Revisão Técnica Sérgio Gadelha Souto; Colaboração: CAOP Infância e Juventude. 2. ed., rev. e atual. - Recife: Procuradoria Geral de Justiça, 2019.

SILVA, Lázara Cristina da et al. Políticas e práticas de formação continuada de professores para Educação Especial: alguns olhares sobre o curso de extensão "Professores e surdez: cruzamento caminhos, produzindo novos olhares. Uberlândia: EDUFU, 2010. 